\title{
Sequence similarity between HLA-DR1 and DR4 subtypes associated with rheumatoid arthritis and proteus/serratia membrane haemolysins
}

\author{
A Ebringer, P Cunningham, K Ahmadi, J Wrigglesworth, R Hosseini, C Wilson
}

\begin{abstract}
Rheumatoid arthritis (RA) is found more often in subjects carrying the HLA-DR1 antigen and some subtypes of the HLA-DR4 antigen than in those without these antigens. Analysis of probes specific for HLA-DR4 has shown that amino acids encoding positions 69-74 (EQRRAA) of the $\beta$ chain indicates susceptibility to RA. A hexamer sequence of proteus haemolysin spanning residues 3237 (ESRRAL) has been identified which resembles biochemically, and discriminates by charge, between HLA types associated with RA (DR1, Dw4, Dw14, Dw15), and those not linked with the disease (Dw10, Dw13).
\end{abstract}

(Ann Rheum Dis 1992; 51: 1245-1246)

The association between rheumatoid arthritis (RA) and the HLA-DR4 antigen is well established, not only in white subjects but also in many other ethnic groups. HLA-DR4 can be subdivided into several subtypes, only some of which are associated with RA. In white subjects DR4/Dw4 and DR4/Dw14 subtypes are associated with RA, whereas in Japanese subjects it is DR4/Dw15 that is the susceptibility factor. In Israeli Jews, where DR4/Dw10 predominates, an association with HLA-DR1 has been reported. ${ }^{2}$

Analysis with synthetic oligonucleotides has shown that a particular sequence from positions
70-74 encoding the amino acids Gln-Arg-ArgAla-Ala (QRRAA), specific for DR1, Dw14, and Dw15, showed a strong association with RA compared with controls, although another probe specific for Dw10 showed no such association. ${ }^{3}$ Glutamic acid (E), occupying position 69 , is common to all DRB1 molecules and could affect the sequence determining disease susceptibility. Examination of serum samples obtained from patients with active RA in London, ${ }^{4}$ Dublin, ${ }^{5}$ and Newcastle ${ }^{6}$ have shown that they have increased levels of antibodies against proteus but not against klebsiella or Escherichia coli and this could be relevant in the aetiology of the disease. ${ }^{7}$ As it appears that patients with active RA have been infected in the past by proteus microorganisms, it is possible that there may be a sequence in these bacteria which resembles the susceptibility sequence in RA.

\section{Methods and results}

The RA susceptibility sequence spanning residues 69-74 (EQRRAA) was used to scan published sequences of molecules from proteus microorganisms. No hexamer identity could be found in the Genbank database, but a closely related sequence (ESRRAL) spanning residues 32-37 of the surface membrane haemolysin of Proteus mirabilis ( $\mathrm{Hpm} \mathrm{B} \mathrm{polypeptide)} \mathrm{was}$ identified which had biochemical and charge similarity to the susceptibility sequence (table).

A similar sequence was found in the membrane
Division of

Biomolecular Sciences and Computer Centre,

King's College,

London and

Department of

Rheumatology,

University College and

Middlesex School

of Medicine,

London W1,

United Kingdom

A Ebringer

$P$ Cunningham

K Ahmadi

J Wrigglesworth

R Hosseini

C Wilson

Correspondence to:

Dr A Ebringer,

Division of

Biomolecular Sciences,

King's College,

London W8 7AH,

United Kingdom.

Accepted for publication 1 July 1992

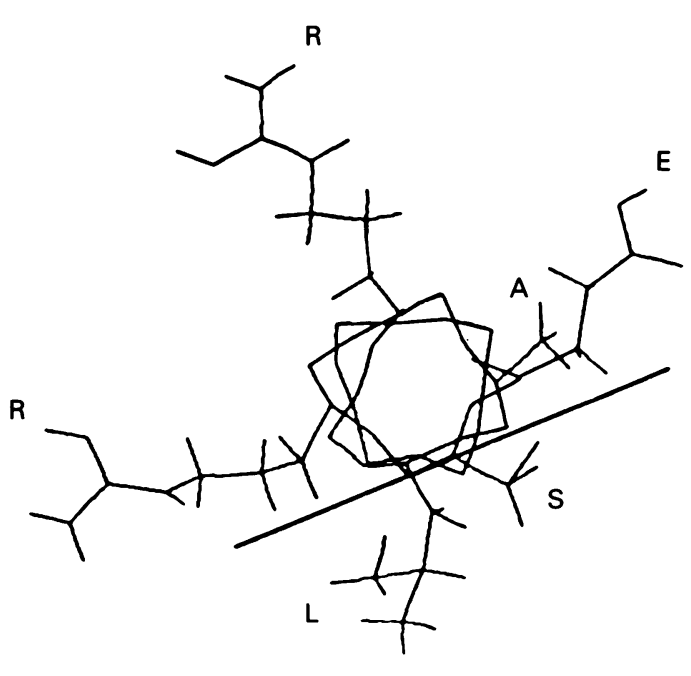

ESRRAL

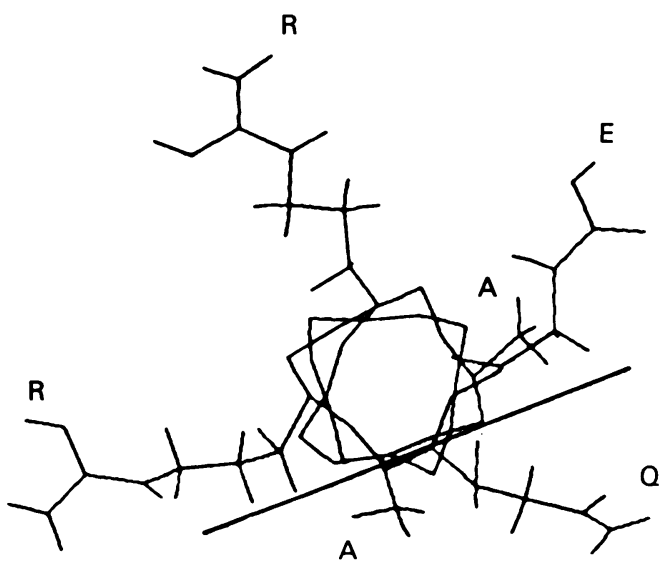

EQRRAA

Helical models of ESRRAL and EQRRAA sequences. The predicted structures show a common charged surface of homologous residues available for immune interaction (above line). Modelling by DTMM (version 1.2)." 
Comparison of the charge distribution ( $+=$ positive; $-=$ negative; $N=$ neutral) of the amino acid sequences of HLA-DRI and DR4 molecules with the similarity sequence in proteus membrane haemolysin

\begin{tabular}{|c|c|c|c|c|c|c|c|}
\hline \multirow[t]{2}{*}{ Disease link } & \multicolumn{6}{|c|}{ Amino acid positions } & \multirow[t]{2}{*}{ HLA subtype } \\
\hline & 69 & 70 & 71 & 72 & 73 & 74 & \\
\hline Associated with RA & $\begin{array}{l}- \\
- \\
-\end{array}$ & $\begin{array}{l}\mathbf{N} \\
\mathbf{N} \\
\mathrm{N}\end{array}$ & $\begin{array}{l}+ \\
+ \\
+\end{array}$ & $\begin{array}{l}+ \\
+ \\
+\end{array}$ & $\begin{array}{l}\mathbf{N} \\
\mathrm{N} \\
\mathrm{N}\end{array}$ & $\begin{array}{l}\mathbf{N} \\
\mathbf{N} \\
\mathrm{N}\end{array}$ & $\begin{array}{l}\text { DR1, Dw14, Dw15 } \\
\text { Dw4 } \\
\text { Proteus haemolysin }\end{array}$ \\
\hline Not associated with RA & $\begin{array}{l}- \\
-\end{array}$ & $\overline{\mathrm{N}}$ & - & + & $\underset{N}{N}$ & $\mathrm{~N}$ & $\begin{array}{l}\text { Dw10 } \\
\text { Dw13 }\end{array}$ \\
\hline
\end{tabular}

haemolysin of Serratia marcescens (Shl B polypeptide $)^{8}$ but not in the haemolysins produced by 10 other bacteria, including $E$ coli.

The haemolysin molecule of proteus is composed of two polypeptides, $\mathrm{Hpm} \mathrm{B}$ and Hpm A, with molecular weights of 63 and 165 kilodaltons respectively. The $\mathrm{Hpm} B$ polypeptide is necessary for the extracellular secretion and activation of the structural haemolysin $\mathrm{Hpm} \mathrm{A}$ and is thought to be located in the outer membrane. The ESRRAL sequence, which is situated close to the amino terminal of the $\mathrm{Hpm}$ B polypeptide, is predicted to be antigenic, extremely hydrophilic, and in an $\alpha$ helix. Molecular modelling of EQRRAA and ESRRAL motifs illustrates that the two sequences can be fitted to similar configurations producing almost identical antigenic epitopes (figure).

\section{Discussion}

The susceptibility sequence found in DR1, Dw14, and Dw15 alleles closely resembles that in Dw4, there being only one conserved amino acid interchange at position 71 from arginine to lysine. These two amino acids are positively charged and thus the overall shape and charge configuration of these two sequences are similar. In contrast, the Dw 10 haplotype has an aspartic acid at position 70 and glutamic acid at position 71 , thereby giving a net negative charge to the sequence, whereas Dw13 has a glutamic acid at position 74

The similarity sequence of proteus membrane haemolysin has the same charged amino acids arranged in the same order as the susceptibility sequence of DR1, Dw14, and Dw15 allelesthat is, a glutamic acid followed by a small neutral amino acid (serine) and then two positively charged arginines. The three charged amino acids of the proteus sequence may provide an immunogenic group with a hydrophilicity value of $+7 \cdot 0,{ }^{10}$ thereby indicating that it could affect immune interaction.

The important question is whether the proteus peptide does indeed take up the predicted structure. If an antibody were to be produced against the similarity sequence of the proteus haemolysin membrane protein, it may bind more readily to the DR1, Dw14, and Dw15 sequences, in addition to the Dw4, but not to Dw10 or Dw13 as there are significant charge differences between these sequences. Thus the proteus haemolysin sequence discriminates between alleles of HLA-DR1 and DR4 that are and are not associated with RA. Whether such an antibody activates the complement cascade or stimulates natural killer cells, thereby producing tissue damage, remains to be determined. Experimental studies are required to confirm that antibodies to the similarity sequence will discriminate between the susceptible alleles of HLA-DR4 and to determine whether such antibodies can be found in patients with active RA.

We thank the Trustees of the Middlesex Hospital and the Arthritis and Rheumatism Council for their support.

1 Stastny P. Association of the B-cell alloantigen DRW4 with rheumatoid arthritis. $N$ Engl $\mathcal{F}$ Med 1978; 298: 869-71.

2 Maeda H, Juji T, Mitsui H, Sonozaki H, Okitsu K. HLADR4 and rheumatoid arthritis in Japanese people. Ann Rheum Dis 1981; 40: 299-302.

3 Watanabe Y, Tokunaga K, Matsuki K, et al. Putative amino acid sequence of HLA-DRB chain contributing to rheumatoid arthritis susceptibility. $\mathcal{F}$ Exp Med 1989; 169: 2263-8.

4 Ebringer A, Ptaszynska T, Corbett M, et al. Antibodies to proteus in rheumatoid arthritis. Lancet 1985; ii: 305-7.

5 Rogers P, Hassan J, Bresnihan B, Feighery C, Whelan A Antibodies to proteus in rheumatoid arthritis. $\mathrm{Br} f$ Rheumatol 1988; 29 (suppl 2): $90-4$.

6 Deighton C M, Gray J W, Bint A J, Walker D J. Anti-proteus antibodies in rheumatoid arthritis same-sexed sibships. $B r$ f Rheumatol 1992; 31: 241-5.

7 Ebringer A, Khalafpour S, Wilson C. Rheumatoid arthritis and proteus: a possible aetiological association. Rheumato Int 1989; 9: 223-8.

8 Uphoff T'S, Welch R A. Nucleotide sequencing of the proteus mirabilis calcium independent haemolysin genes (hpm A and hpm B) reveals sequence similarity with the Serratia marcescens haemolysin genes (shl A and shl B). f Bacteriol 1990; 170: 3177-88.

9 D T M M version 1.2, Oxford: Oxford University Press.

10 Hopp T P, Woods K R. Prediction of protein antigenic determinants from amino acid sequences. Proc Natl Acad Sci USA 1981; 78: 3824-8. 